\title{
Interseismic Strain Accumulation on the Himalayan Crustal Ramp (Nepal)
}

\author{
M.R. Pandey, R.P. Tandukar, \\ Seismological laboratory, Department of Mines and Geology,Kathmandu, Nepal
}

\author{
J.P. Avouac, J. Lavé and J.P. Massot \\ Laboratoire de Géophysique, CEA, Bruyères-le-Châtel, France
}

\begin{abstract}
The Departement of Mines and Geology has been monitoring the seismicity of the Central Himalayas of Nepal since 1985. Intense microseismicity and frequent medium-size earthquakes $(\mathrm{mL}<4)$ tend to cluster beneath the topographic front of the Higher Himalaya. This $10-20 \mathrm{~km}$ deep seismicity also correlates with a zone of localized uplift that has been evidenced from geodetic data. Both microseismic and geodetic data indicate strain accumulation on a mid-crustal ramp that had been previously inferred from geological and geophysical evidence. This ramp connects a flat decollement under the Lesser and SubHimalaya with a deeper decollement under the Higher Himalaya, and probably acts as a geometric asperity where strain and stress. build up during the interseismic period. The large Himalayan earthquakes could nucleate there and probably activate the whole flat-and-ramp system up to the blind thrusts of the Sub-Himalaya.
\end{abstract}

\section{Introduction}

Nearly half of the Himalayan chain ruptured over the last century producing four earthquakes with magnitude around 8.5 in 1897 , 1905, 1934 and 1950 [e.g.,Seeber and Ambuster, 1981; Molnar and Pandey, 19891. The central Himalaya of Nepal, between $\mathrm{N} 79^{\circ} \mathrm{E}$ and $85^{\circ} \mathrm{E}$ of longitude, was not activated during this period (Figure 1) and thus stands as a potential location for the next large himalayan earthquake. Historical records indicate that the Kathmandu valley has experienced recurring large earthquakes in the past centuries. Major damages of probably seismic origin are reported to have occurred in $1255,1408,1681,1803,1810,1833$, 1866 [Chitrakar and Pandey, 1986]. Some of these events might be related to the repetition in the past of the 1934 Bihar-Nepal earthquake that ruptured a 200 to $300 \mathrm{~km}$ long segment of the Himalayan arc to the east of Kathmandu [Pandey and Molnar, 1988]. Others might be related to rupture of a segment along the central Himalaya of Nepal, west of Kathmandu, or to smaller magnitude earthquakes that would have occurred close to the Kathmandu valley. Because recurrence intervals and segmentation of the Himalayan arc are poorly constrained from historical and quaternary geology the seismic hazard can be only roughly evaluated. To be able to mitigate this risk, the Department of Mines and Geology (HMG, Nepal), in collaboration with the Laboratoire de Géophysique (CEA, France) has been monitoring the seismic activity in central Nepal since 1985. Hereafter, we first present some characteristics of the seismic network of Nepal. We next discuss the seismicity data collected between 1985 and 1993 in view of the geophysical and geological informations about the structure of the Himalayas of Nepal. In particular, we provide evidence that during the 10 year long seismicity monitoring, strain has accumulated in the vicinity of a mid-crustal ramp beneath the Higher Himalaya.

Copyright 1995 by the American Geophysical Union.

\section{Capabilities of the seismological network of central Nepal}

The seismological network around Kathmandu valley consists of 5 vertical short period stations that are telemetered in real time to a processing center in Kathmandu (Figure 2). This network has been in operation since 1985 and was upgraded in 1994. It now consists of 17 stations covering the whole territory of Nepal (Figure 2). The detection capability of the 5-stations network around Kathmandu is about a local magnitude $M_{L}=1$ for events within the network, and about $M_{L}=3$ for events in the far-western or fareastern Nepal, 200 to $300 \mathrm{~km}$ away from the network.

\section{Velocity Model}

A three layer 1-D model is used for routine processing (Table 1). This model has been determined from the study of quarry blasts and from the distribution of apparent velocity of the first arriving phases generated by microseismic events occurring from a few kilometers to regional distance within the extent of the lesser Himalaya [Bouvier, 1981; Pandey, 1985]. Although the structure of the range is not unidimensionnal, this simple model was found consistent with ray tracing modeling [Pandey, 1985]. It is also consistent with computed crustal thickness and velocity in the Lesser Himalaya determined from deep seismic profiling [Hirn et al., 1984]. Most of the microseismicity activity observed from 1985 to 1993 has occurred within the Lesser Himalaya where the velocity model has been constrained and justified.

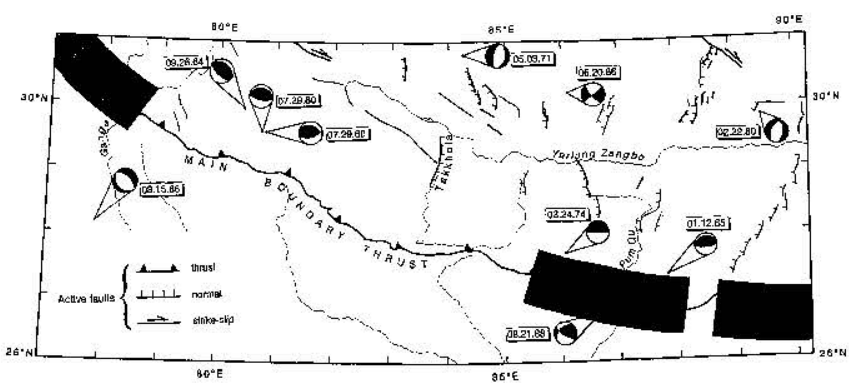

Figure 1: Sismotectonic map of Central Himalaya. Probable rupture zones of 1897,1905 , and 1934 earthquakes are shown by shaded areas (modified from Armijo et al., 1986; Seeber and Armbruster, 1981; Molnar and Lyon-Caen, 1989, and Molnar and Pandey, 1989). Fault plane solution of the 22/08/1988 event from Pandey and Nicolas [1989].

Table 1: velocity model for central Nepal

\begin{tabular}{lll}
\hline layer & $\mathrm{Vp}(\mathrm{km} / \mathrm{s})$ & $\mathrm{Vs}(\mathrm{km} / \mathrm{s})$ \\
\hline $0-23 \mathrm{~km}$ & 5.6 & 3.2 \\
$23-55 \mathrm{~km}$ & 6.5 & 3.7 \\
$>55 \mathrm{~km}$ & 8.1 & 4.6
\end{tabular}




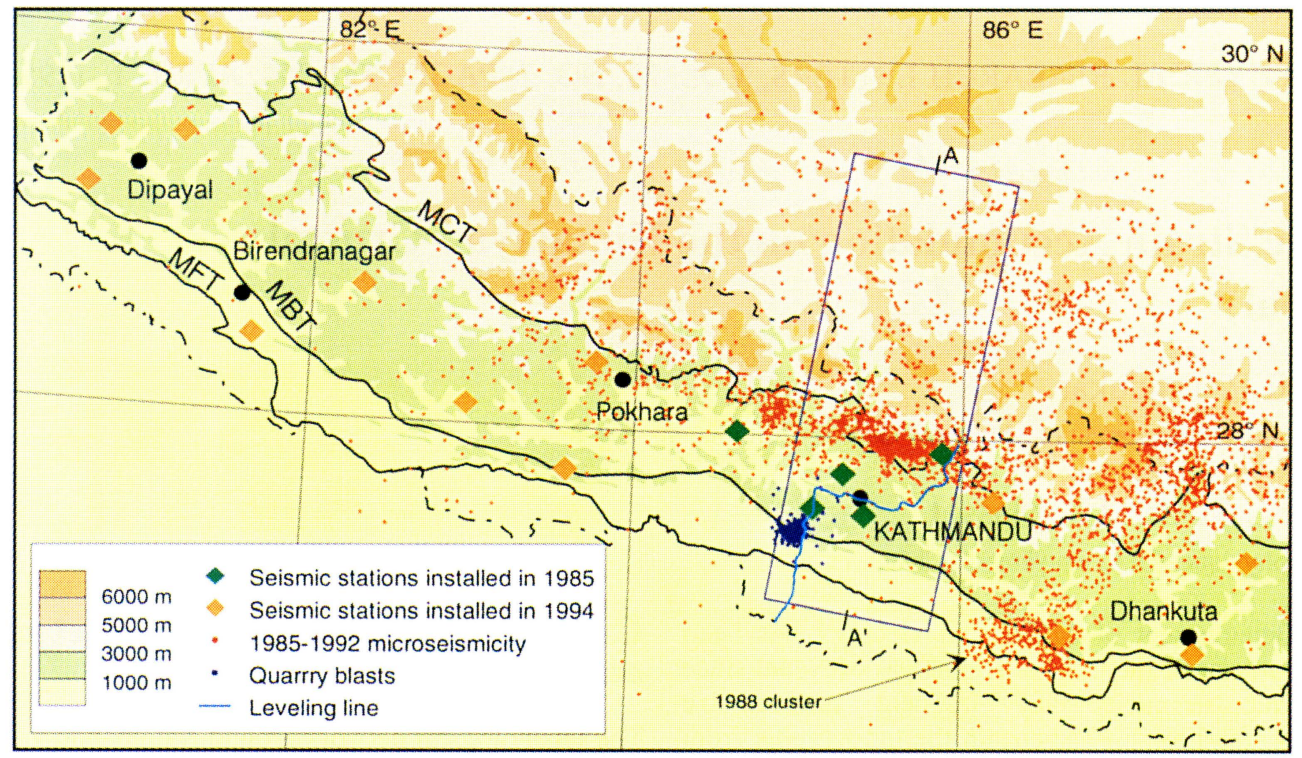

Figure 2: Microseismicity map of central Nepal recorded between 1985 and 1993. AA' shows location of cross section in Figure 3 Box indicate the area considered in Figure 4.

\section{Uncertainties on epicentral determinations}

In order to have some direct estimate of the uncertainties on epicentral determinations, we have compared routinely obtained locations of 256 events that appeared to be quarry blasts detonated at a limestone quarry north of Hetauda (Figure 2). The barycenter of the events is located $5.8 \mathrm{~km}$ to the southwest of the quarry and the standard deviation is of $9 \mathrm{~km}$. Given that quarry blasts do not generally generate clearly visible $\mathrm{Sg}$ waves, this bias could be due to mis-interpretation of Sn waves in terms of Sg waves. This bias could therefore be specific to quarry blasts. Calculated depths varies between 0 and $20 \mathrm{~km}$ with a mean of $9 \mathrm{~km}$ and a standard deviation of $8 \mathrm{~km}$. Given that these events are located somewhat outside the network we consider that epicentral determinations for the events within, or near the edge of the network, might be in error of $10-15 \mathrm{~km}$ at the $1-\sigma$ confidence level. Similarly we estimate focal depth obtained for event at the edge of the network to be uncertain by about $10 \mathrm{~km}$ at the $1-\sigma$ confidence level. Within the network we estimate the location inaccuracy to be of a few kilometers horizontally and little more than about 5 kilometers vertically.

\section{Central Nepal seismicity}

Out of the 4000 local events recorded between 1985 and 1992, 1200 events occurred within the network (Figure 2). Most of them are shallow microseimic events with local magnitude below 4 . Only one local moderate earthquake has been recorded during this time period. This event with magnitude $\mathrm{mb}=6.1, \mathrm{Ms}=6.5$ occurred on 21 August 1988 . It was located at $26.78^{\circ} \mathrm{N} 86.61 \mathrm{E}$, at an unusual depth of about $57 \mathrm{~km}$ and the fault plane solution indicates thrusting on a SE striking reverse fault [Pandey and Nicolas, 1989] (Figure 1). If we except the cluster of aftershocks around the 21/8/1988 main event, the sub-himalayan zone has been relatively quiet. In particular there has been no detectable shallow microseismic activity associated with the active thrust faults in the Sub-Himalaya. Somewhat away from the network, we observe two zones of seismicity that form north-south trending zones at about $\mathrm{N} 83.5^{\circ} \mathrm{E}$ and $\mathrm{N} 87.5^{\circ} \mathrm{E}$ of longitude. Although locations are very poorly constrained there, these zones seem to coincide with known tectonic features that saddle across the high himalayan range. One is the Takkhola graben, west of Kathmandu, and the other is the graben along the Pum Qu River east of Kathmandu (Figures 1 and 2). The most outstanding and well constrained feature in the seismicity map is the clustering of microseismic events along the foothill of the Higher Himalaya. It makes an east-west trending zone that roughly follows the trace of the Main Central Thrust. The seismicity map is somewhat biased because the detection threshold is higher for events within the network and decreases away from it. But since the cluster of events can be seen to lie a few tens of kilometers to the north of the network we consider that this feature cannot be an artefact due to network detection capability. Uncertainties on locations and depth determinations are probably of the same order of magnitude or somewhat lower than those estimated for the quarry blast at

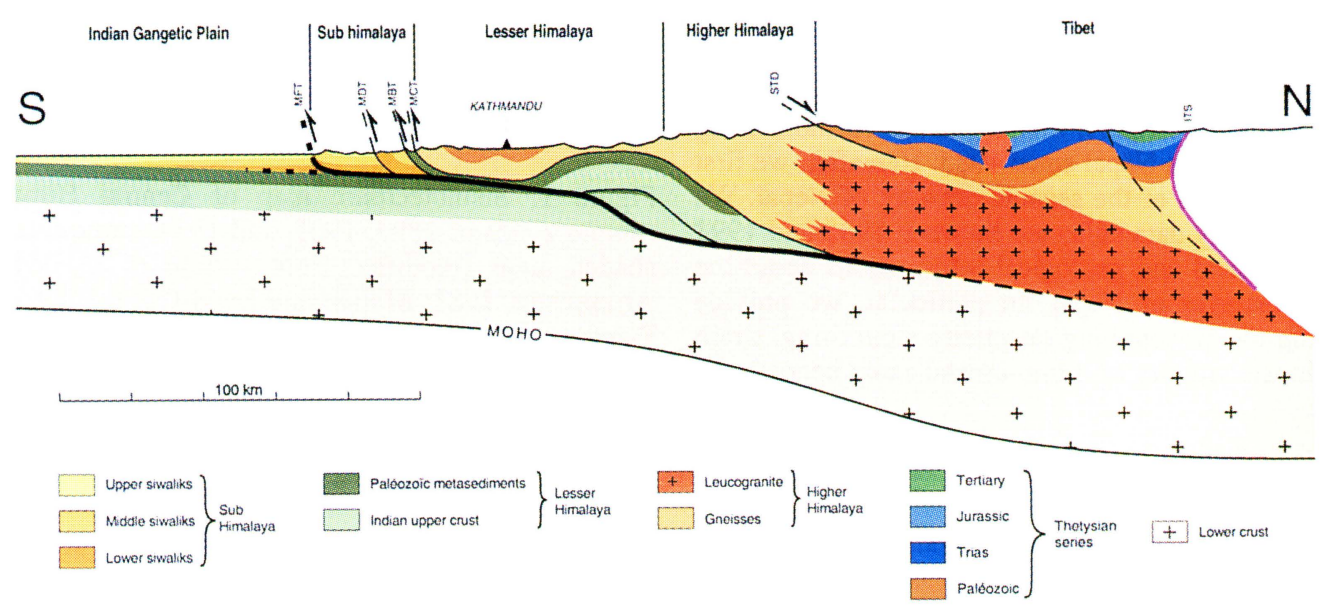

Figure 3: N10 ${ }^{\circ} \mathrm{E}$ section across the central Himalaya of Nepal. Geology modified from Brunel [1986] and Schelling [1992]. Topography from ONC (G7). 

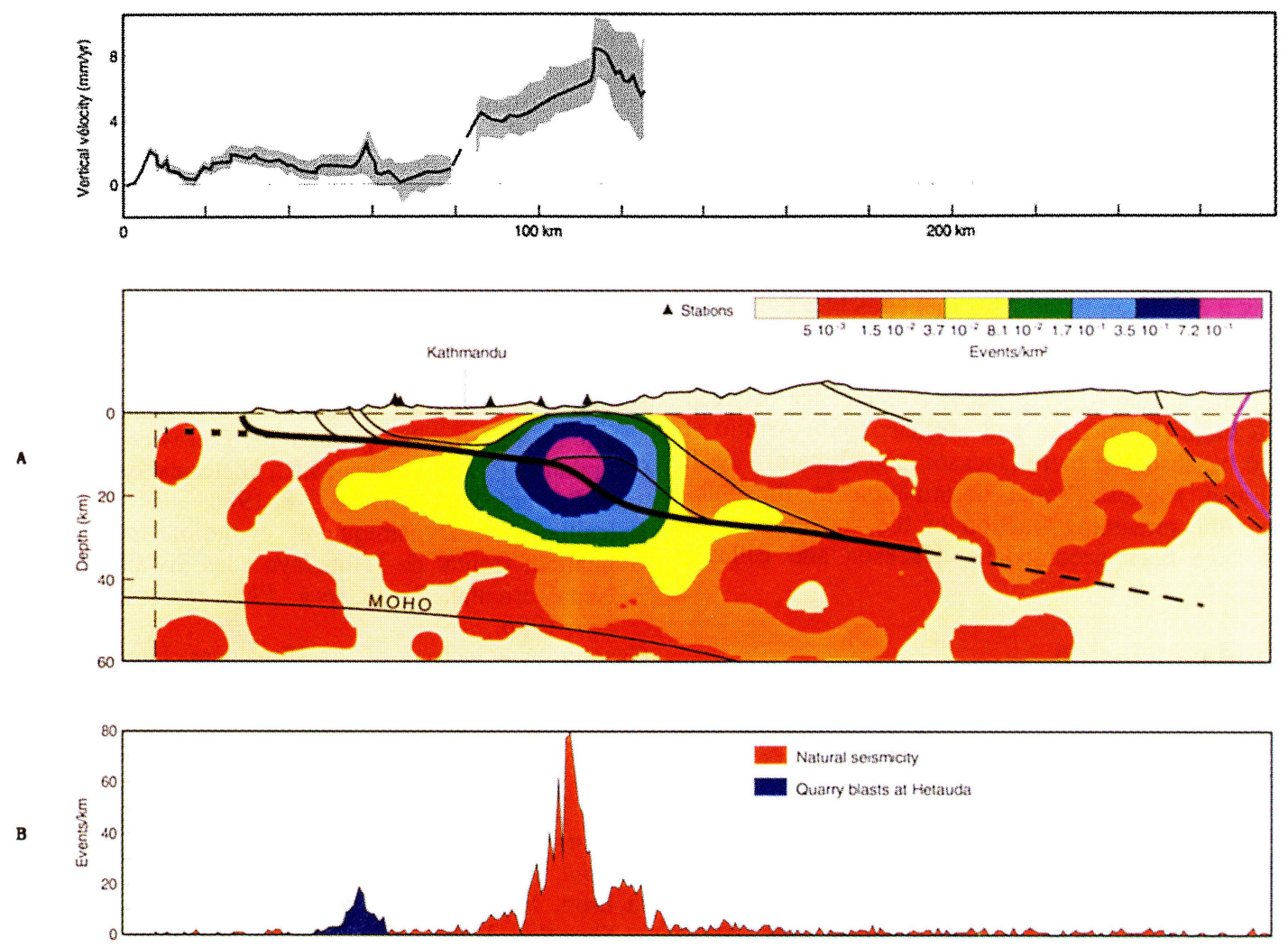

Figure 4: (A) Density distribution of seismic events along $\mathrm{AA}^{\prime}$ section. All natural seismic events with resolvable depths and within $50 \mathrm{~km}$ of section $\mathrm{AA}^{\prime}$ (see box in Figure 2) have been considered. In order to take into account uncertainties on seismic locations the resulting distribution has been filtered using an axisymetric Gaussian filter with $\sigma=5 \mathrm{~km}$ (The effect of the filter is to simulate the distribution probabilitity on seismic locations). Note the logarithmic scale for density of microseismic events. Fault geometries reported from Figure 3. (B) Density distribution of seismic events along AA'. All events have been considered including quarry blasts at Hetauda and events with unresolved depths. (C) Vertical velocities .deduced from geodetic measurements along the levelling line of Figure 2, from Jackson and Bilham [1994].

Hetauda (the quarry lies about $15 \mathrm{~km}$ south of the southernmost station). In addition, this cluster has been a permanent feature over the 8 year monitoring and is not related to any particular seismic crisis. We therefore infer this seismicity feature to reflect some particular tectonic process that has been active over the last decade.

\section{Comparison with geological and geodetic data}

\section{Structure of the Himalaya of Central Nepal.}

Figure 3 shows a $\mathrm{N} 10^{\circ} \mathrm{E}$ cross-section across the Himalaya of Nepal at the longitude of Kathmandu that has been drawn on the basis of detailed sections that have been published for the Himalaya of Nepal [e.g., Brunel, 1986;Delcaillau, 1986; Schelling and Arita, 1991]. The Sub-Himalaya is a zone of piedmont folds that formed in the Siwaliks cenozoic molasse. It is bounded to the south by an active thrust fault, the Main Frontal Thrust [Nakata, 1989] and to the north by the Main Boundary Fault that has thrusted Lesser Himalaya metasediments over the Siwaliks [e.g., Gansser, 1964]. Abundant outcrops of Lower Siwaliks together with very few outcrops of Sub-Siwaliks rocks in the SubHimalaya suggest a decollement at the base of the $\sim 5-6 \mathrm{~km}$ thick Siwaliks sediments. Structural cross sections indicates that the Main Frontal Thrust and the main Dun Thrust must root into this decollement [e.g., Delcaillau, 1986; Shelling and Arita, 1991]. From the analysis of great detachement earthquakes and of focal depth determination of medium size earthquakes, it has been proposed that the Sub-Himalayan decollement prolongates northwards under the Lesser Himalaya [Seeber and Armbuster, 1981; Ni and Barazangi, 1984; Baranowski et al., 1984]. This is consistent with the Main Boundary Fault flattening out at depth, as suggested from northward flattening of foliation planes in the Lesser Himalya [Schelling and Arita, 1991]. Farther north the detachement fault under the Lesser Himalaya probably steepens beneath the Higher Himalaya [Seeber and Armbuster, 1981; Ni and Barazangi, 1984]. This ramp geometry would be responsible for the steepening of the foliation planes with nortward dips in the northern Lesser Himalaya [Shelling and Arita, 1991]. In Figure 3, we have opted for a duplex structure in the Lesser Himalaya essentially for consistency with the "balanced" section of eastern Nepal proposed by Schelling and Arita [1991], although the basic hypothesis allowing for line-length restoration probably do not hold for ductily deformed rocks. Other geometries could be advocated as well and would result only in a slight shift of the position of the ramp.. Additional and independant observations such as variation of terraces heights along the Kali Gandaki [Iwata et al., 1984; Molnar, 1987], or steepening of the Moho inferred from gravity anomalies [Lyon-Caen and Molnar, 1985] also attest for the existence of this active ramp. Uplift due to slip along this relatively steep ramp would moreover have maintained the continuously eroded steep front of the Higher Himalaya and brought to the surface high grade metamorphic rocks [Molnar, 1987]. Farther north the mid-crustal ramp is assumed to root into a deeper decollement under the Higher Himalaya, that could correspond the $30-40 \mathrm{~km}$ deep seismic reflector imaged during the INDEPTH experiment [Zhao et al., 1993]. The faults geometries of Figure 3 have been reported in Figure 4A which also shows the density of seismic events within a $100 \mathrm{~km}$ wide zone centered on the section. Most seismic events are seen to cluster at shallow depths, between 5 and $20 \mathrm{~km}$, in the vicinity of the midcrustal ramp beneath the Higher Himalaya. We therefore propose that the microseismic activity recorded at the front of the Higher Himalaya over the last decade has resulted from stress accumulation at the mid-crustal ramp. 


\section{Geodetic data}

A leveling line that connects India to China across the Himalaya of Nepal has been levelled twice between 1976 and 1991 by the HMG Survey Department [Jackson et al., 1992; Jackson and Bilham, 1994] (Figure 4C). The time span and the area covered by the geodetic and microseimic data thus roughly coincide. The geodetic data yield some deformation signals slightly above the random noise level [Jackson et al., 1992]. They would in particular indicate some localized uplift at the front of the Higher Himalaya making a $30-40 \mathrm{~km}$ broad zone that coincides both with the mid-crustal ramp and with the zone of intense microseimic activity (Figure 4). Modeling of geodetic data further indicates that about two thirds of the $-15-20 \mathrm{~mm} / \mathrm{yr}$ convergence between Tibet and stable India [Lyon-Caen and Molnar, 1985; Armijo et al., 1986] would be absorbed there [Jackson and Bilham, 1994]. Geodetic data also suggests some deformation in the SubHimalaya, where the remaining fraction of the convergence ( $5 \mathrm{~mm} / \mathrm{yr}$ ) could have been accomodated [Jackson and Bilham, 1994].

\section{Discussion and conclusion}

Geodetic and microseismic data over the last decade show strain and stress accumulation at the mid-crustal ramp beneath the Higher Himalaya. The mid-crustal ramp thus seems to behave, during interseismic periods, as a geometric asperity where accumulation of elastic strain would account for as much as two thirds of the present convergence between India and Tibet. In the long term, however, most of the deformation is expressed by thrusting and folding in the Sub-Himalaya [Molnar and LyonCaen, 1988; Lyon-Caen and Molnar, 1985]. The seimic cycle along this part of the Himalaya thus probably involves interseismic period during which stress and strain build up at the crustal ramp, and large seismic events that would release the elastically stored part of this deformation and allow transfer of the deformation ahead of the asperity. A bimodal distribution of seismicity is currently observed along the Himalaya with relatively frequent earthquakes with magnitude between 6 and 7 and less frequent very large earthquakes with magnitudes above 8 . The events with magnitude between 6 and 7 are characterized by 10$15 \mathrm{~km}$ focal depths and may activate either the decollement beneath the Lesser Himalya or the upper part of the ramp as indicated from either sub-horizontal or steep fault planes dipping to the north [Baranowski et al., 1984; $\mathrm{Ni}$ and Barazangi, 1984]. These events would transfer ahead of the ramp-flat transition some of the interseismic deformation accumulated at the ramp. This deformation could be partly irreversibly absorbed by aseismic incremental folding or elastically stored until it is released by the larger earthquakes that probably activate the whole ramps and flats sytem up to the most frontal structures as it has actually been observed for the 1905 Kangra earthquake [Yeats and Lilly, 1991]. After initiation of faulting, probably in the vicinity of the rampflat transition, an event might evolve into a very large or medium size earthquake depending on the amount of elastic strain stored ahead of the ramp-flat transition. The very large events probably account for the bulk of the deformation that is transferred to the most frontal structures in the Sub-Himalaya. The seismic behavior described in this study could also hold for smaller scale structures such as the El Asnam thrust system or for other active mountain belt such as the Alpes, the Tien Shan in central Asia or the San Gabriel in California [Avouac et al., 1992, 1993].

Acknowledgments. We thank the technical teams at the LDG and DMG for installation and careful maintenance of the nepalese seismic network. Francis Guillois drafted the Figures. We thank Roger Bilham for comments, Robin Lacassin and one anonymous reviewer for useful reviews.

\section{References}

Armijo, R., P. Tapponnier, J.L. Mercier, and H. Tonglin, Quaternary extension in Southern Tibet, J. Geophys. Res., 91, 13803-13872, 1986.
Avouac, J.P., P. Tapponnier, M. Bai, H. You and G. Wang, Active thrusting and folding along the northeastern Tien Shan and late Cenozoic rotation of Tarim with respect to Dzungaria and Kazakhstan, J. Geophys. Res., 98, 6755-6804, 1993.

Avouac, J.P., B. Meyer and P. Tapponnier, On the growth of normal faults and the existence of flats and ramps along the $\mathrm{El}$ Asnam active fold and thrust system, Tectonics, 11, 1-11, 1992.

Baranowski, J., Armbuster J., Seeber L. and Molnar P., Focal depths and fault plane solutions of earthquakes and active tectonics of the Himalaya, J. Geophys. Res., 89, 6918-6928, 1984.

Bouvier, Première étude du réseau sismique népalais. Thèse de Doctorat Paris VI, 1981.

Brunel, M., Ductile thrusting in the Himalayas: shear sense criteria and stretching lineations, Tectonics, 5, 247-265, 1986.

Chitrakar G.R. and Pandey M.R., Historical earthquakes of Nepal, Bull. Geol. Soc. Nepal, 4, 7-8, 1986.

Delcaillau, B., Dynamique et evolution morphostructurale du piemont frontal de l'Himalaya : les Siwalik de l'Himalaya du Nepal oriental, Rev. Georg. Phys et Geol. Dynam., 27, 319$337,1986$.

Gansser, A., Geology of the Himalayas, Inter-Science Publisher, 1964.

Hirn, A., M. Sapin, J.C. Lépine, Z.X. Xu, E.Y. Gao, J.W. Teng, and M.R. Pandey, Himalaya border of Tibet: crustal structure and variability, Nature, 307, 23-25, 1984.

Iwata, S., T. Sharma, H. Yamanaka, A preliminary report on geomorphology of central Nepal and Himalayan uplift, J. Nep. Geol. Soc., 4, 141-149, 1984.

Jackson, M., S. Barrientos, R. Bilham, D. Kyestha and Buddhi Shrestha, Uplift in the Nepal Himalaya revealed by spirit leveling, Geophys. Res. Let., 19, 1539-1542, 1992.

Jackson, M. and Bilham R., Constraints on Himalayan deformation inferred from vertical velocity fields in Nepal and Tibet, J. Geophys. Res., J. Geophys. Res., 99, 13897-13912, 1994.

Lyon-Caen, H. and Molnar P., Gravity anomalies, flexure of the Indian plate and the sructure, support and evolution of the Himalaya and Ganga Basin, Tectonics, 4, 513-538, 1985.

Molnar, P, Inversion of profiles of uplift rates for the geometry of dip-slip faults at depth, with examples from the Alps and the Himalaya, Ann. Geophysicae, 5, 663-670, 1987.

Molnar, and Lyon Caen, Fault plane solutions of earthquakes and active tectonics of the Tibetan Plateau and its margins, Geophys. J. Int., 99, 123-153, 1989.

Nakata, T., Active faults of the Himalaya of India and Nepal, Spec. Pap. Geol. Soc. Am., 232, 243-264, 1989.

$\mathrm{Ni}$, J. and M. Barazangi, Seismotectonics of the Himalayan collision zone: geometry of the underthusting Indian plate beneath the Himalaya, J. Geophys. Res., 89, 1147-1163, 1984.

Pandey, M.R., Seismic model of Central and Eastern Lesser Himalaya of Nepal, J. Geol. Soc. Nep., 3, 1-11, 1985.

Pandey, M.R. and Molnar P., the distribution of intensity of the Bihar-Nepal earthquake of 15 January 1934 and bounds on the extent of the rupture zone, J. Geol. Soc. Nepal, 5, 22-44, 1988.

Pandey, M.R. and M. Nicolas, The afterschok sequence of the Udayapur earthquake of August 90, 1988, J. Geol. Soc Nep., 1989.

Schelling, D. and Arita K., Thrust tectonics, crustal shortening and the structure of the Far-Eastern Nepal Himalaya, Tectonics, $10,851-862,1991$.

Seeber, L. and Armbuster J., Great detachment earthquakes along the Himalayan arc and the long term forecasts, Earthquake Prediction : An International Review, Maurice Ewing Series 4, ed. by D. W. Simpson and P.G. Richards, Am. Geophys. Un., Washington D. C., 259-277, 1981.

Yeats and Lillie, Contemporary tectonics of the Himalayan frontal fault system: folds, blind thrusts and the 1905 Kangra earthquake, J. Struct. Geol., 13, 215-225, 1991.

Zhao, W., K.D. Nelson and Project INDEPTH Team, Deep seismic reflection evidence for continental underthrusting beneath southern Tibet, Nature, 366, 557-559, 1993.

(received september, 9, 1994; accepted october, 10, 1994.) 